\title{
Impact resistance and fragmentation behaviour of glassceramics
}

\author{
SARASWATI VENKATARAMAN \\ Defence Metallurgical Research Laboratory, Kanchanbagh. Hyderabad 500058, India \\ MS received 13 November 1995; revised 19 June 1996
}

\begin{abstract}
Impact tests were carried out on five glassceramics tiles. The ballistic resistance was evaluated by the depth of penetration of the projectile into the backing. The fragmentation behaviour of the glassceramics showed that the glassceramics compared well with alumina and displayed some advantages over it.
\end{abstract}

Keywords. Impact resistance: ballistic resistance; fragmentation; glassceramics.

\section{Introduction}

Glassceramics are light weight materials, lighter than many ceramics and could be considered for weight-saving composite armours. Ceramic armour and silicates in core have been in use throughout the twentieth century, but the details were not published owing to the classified nature of applications. The correlation of impact performance with the physical and mechanical properties of materials are needed to create a database for choosing appropriate materials (Jones and Todhunter 1988). Glassceramics are formable like metals and pore-free compared to ceramics (Macmillan 1979). But conventional steel and aluminum are still the favourites due to their ductility and usability in load-bearing applications and their low cost. The advanced materials like ceramics and polymers offer weight saving but because of high cost their utilization is specialized and performance-driven.

Glassceramics exhibit good ballistic properties against ballrounds and perform better than alumina (Saraswati 1992). Owing to the formability of glass, monolithic pieces with minimized joints and requisite curvatures are possible. In general, armour is for the protection of equipment and personnel. In the consumer sector envisaged usages are, anti-ballistic riot helmets and bomb disposal helmets. This paper reports on the properties and ballistic resistance of some glassceramic $(\mathrm{gc})$ tiles and their coating on alumina. The fragmentation behaviour of the tiles have been analysed. The trials have shown some advantages.

\section{Glassceramic material and properties}

Glassceramics which contain lithium silicates have low densities (Saraswati and Sriram 1989). Hence, several compositions, consisting of lithia, alumina and silica were prepared and tested. They were melted in platinum crucibles and cast as tiles $(6 \mathrm{~cm} \times 6 \mathrm{~cm})$, and were clear, transparent glasses. On heating, few crystalline phases developed and opacified the tiles. Depending on temperatures and their duration, spodumene, lithium disilicate and quartz phases formed in varied proportions. X-ray diffraction (figure 1) and FTIR (figure 2) give information on the respective phases in the glassceramics. Figure 1 shows XRD in glasses of composition a and $b$ after heat treatment at 500,750 and $850 \mathrm{C}$. The heat treatment temperatures were selected to give 


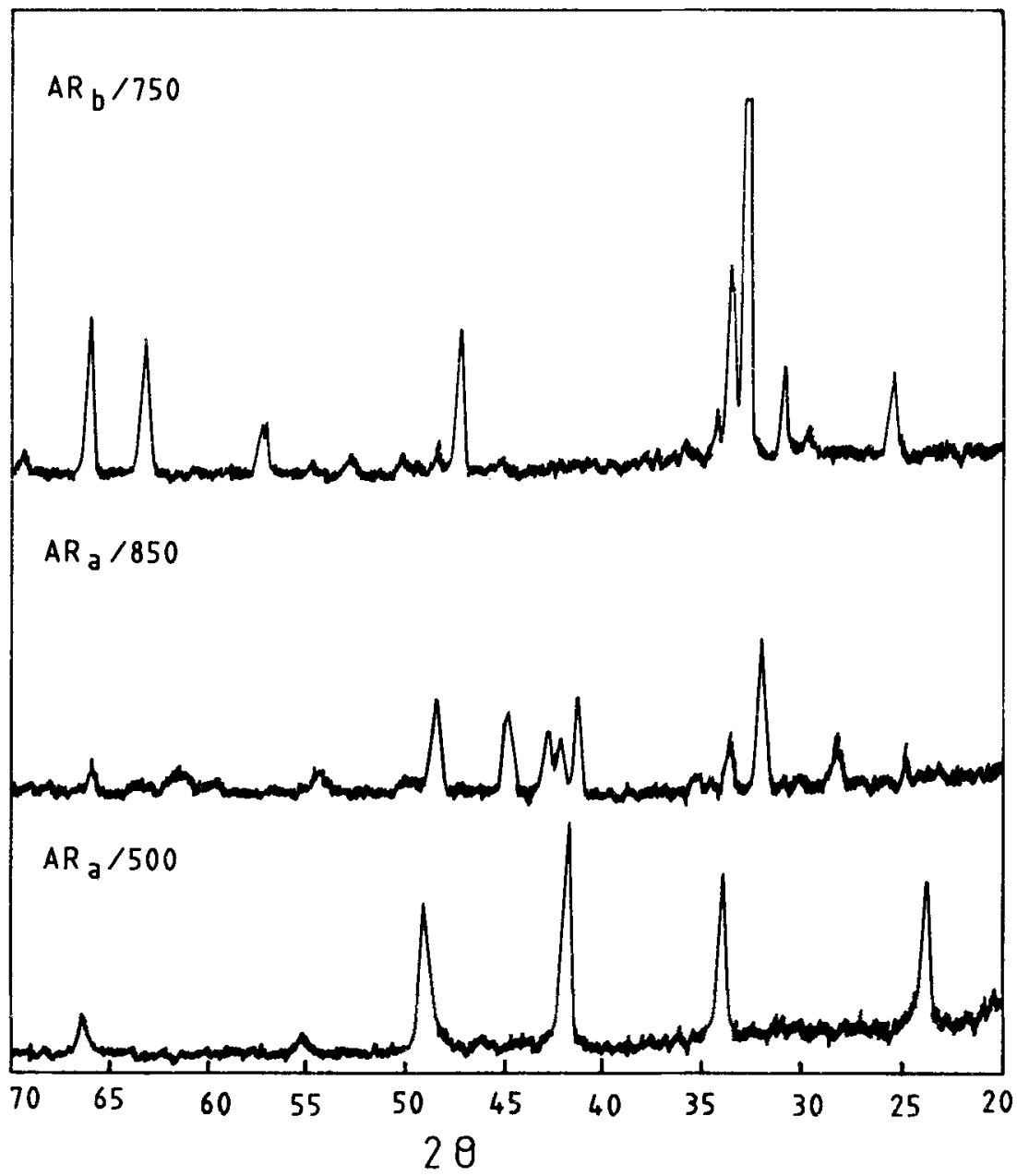

Figure 1. X-ray diffraction of glassceramics $a$ and $b$ after different heat treatments at temperatures indicated.

the desired phase. Figure 2 shows the changes in vibrational modes with the changes in the duration and heat treatment temperatures. The peaks refer to the stretch and bend modes of the silicate groups. Glass shows broad bands. On crystallization at 750 and $800^{\circ} \mathrm{C}$ sharp peaks form. At $900^{\circ} \mathrm{C}$ there is broadening due to formation of quartz solid solution.

A was a glassceramic tile $9.6 \mathrm{~mm}$ thick, B was made of two glassceramic tiles of total thickness $15.1 \mathrm{~mm}, \mathrm{C}$ and $\mathrm{D}$ were alumina tiles coated with precursor glass powders and heated for effective binding and $E$ was alumina tile about 8 to $10 \mathrm{~mm}$ thick. The density, hardness and flexure strength of the tiles A, B, C, D and E (table 1) were dependent on the phases formed. The tiles were cut into rectangular bars for measuring flexure strength. In $C$ and $D$ the glass coating chipped or cracked while cutting. Hence flexure strengths could not be measured in them. The physical and mechanical properties have been measured to find a correlation between quasistatic mechanical properties and ballistic performance. 


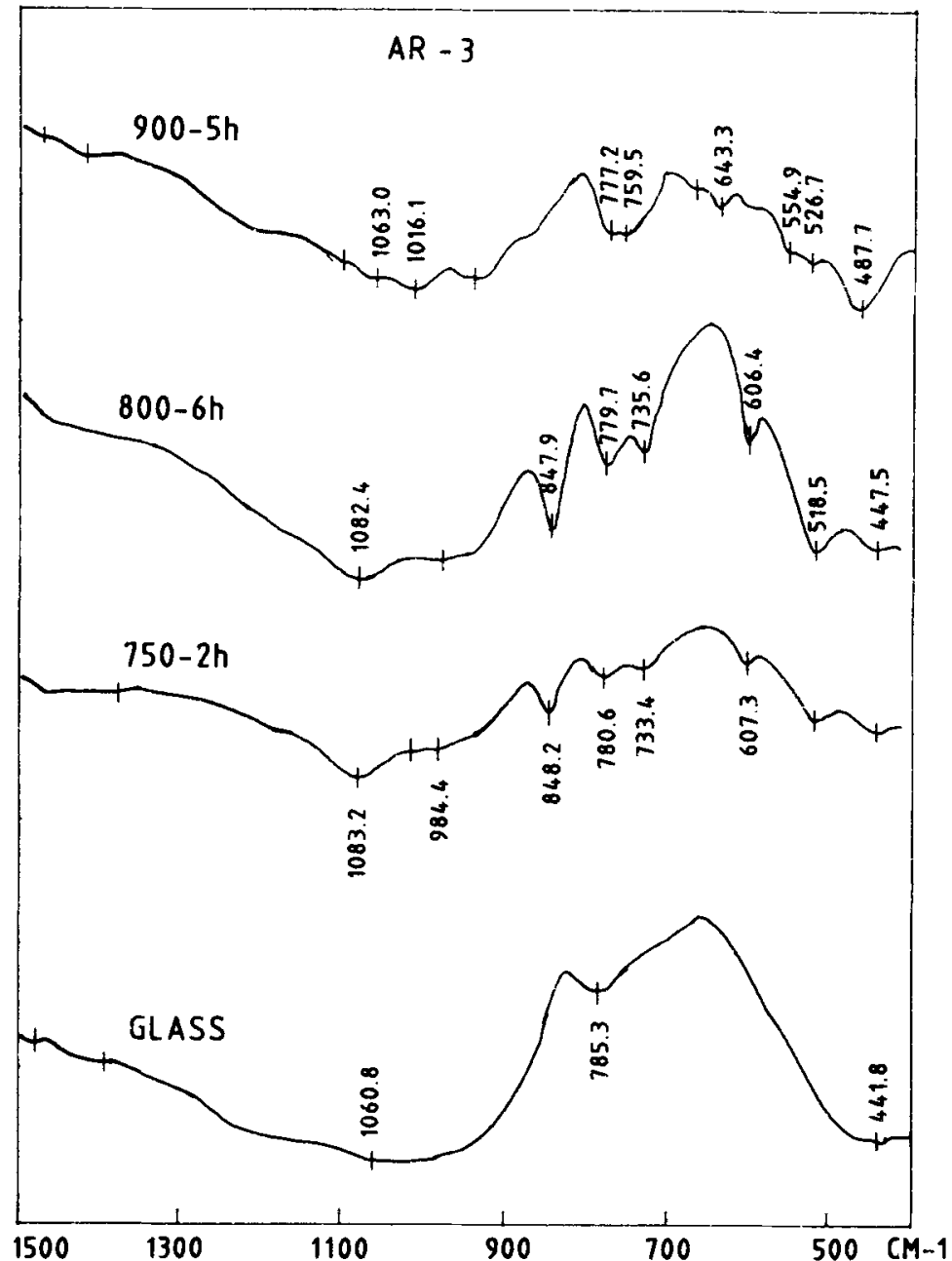

Figure 2. FTIR in the glassceramic AR-3 after different heat treatments at temperatures indicated

Table 1. Characterization and test results on tiles.

\begin{tabular}{lccccc}
\hline Property of tile & A & B & C & D & E \\
\hline Density $(\mathrm{g} / \mathrm{cc})$ & $2 \cdot 48$ & $2 \cdot 48$ & 3.51 & 354 & 3.66 \\
Thickness $(\mathrm{mm})$ & $9 \cdot 6$ & $15 \cdot 1$ & 10.5 & 10.35 & 10 \\
Hardness $\left(\mathrm{kg} / \mathrm{mm}^{2}\right)$ & 630 & 618 & 589 & - & 1600 \\
Flex. strength $(\mathrm{MPa})$ & 102 & 109 &.- & $-\cdots$ & 290 \\
Proj. velocity $(\mathrm{m} / \mathrm{s})$ & 821 & 832 & 830 & 821 & 828 \\
DOP $(\mathrm{mm})$ & 4.4 & 0.4 & 0.6 & 0.5 & 0.5 \\
Areal density & $23 \cdot 8$ & 37.5 & 36.8 & 36.6 & 36.6 \\
$\left(\mathrm{~kg} / \mathrm{m}^{2}\right)$ & & & & &
\end{tabular}




\section{Impact response of ceramic composite armours}

Every armour is designed for a specific threat. A ceramic composite armour consists of a hard ceramic front plate bonded to a ductile backing material. The word ceramics here encompasses all inorganic materials including glass and glassceramics (Laible 1980). The ceramic front is expected to blunt and destroy the impacting projectile, decelerate its momentum and spread the load over a large area of the backing plate, which bends to absorb the kinetic energy. Ductile metals like steel or aluminum, and polymers like kevlar are most useful as supports and for trapping the momentum.

The impact response of materials depend upon the projectile velocities. Roughly, three regimes are considered: (i) low velocities, $v<700 \mathrm{~m} / \mathrm{s}$, (ii) intermediate, $v \sim 700-3000 \mathrm{~m} / \mathrm{s}$ and (iii) hypervelocity, $v>3000 \mathrm{~m} / \mathrm{s}$. At low velocities the mechanical properties, either quasistatic or dynamic, play a role in the penetration of projectile into the target. The fracture mechanisms are dominated by elastic deformations and their interactions with defects in the material. At intermediate velocities, the dynamic and hydrodynamic flow behaviour apply, whereas at hypervelocities fluid dynamics hold good. Our study at velocity about $830 \mathrm{~m} / \mathrm{s}$ is close to the lower limit of the intermediate region and hence mechanical and fracture properties could have a relevance to the ballistic response.

Upon impact the ceramic is fractured in the form of a conoid (Wilkins 1980). When the ceramic fractures the force of impact is spread over a large area i.e. the base of cone. It is followed by a tensile failure in the ceramic, which initiates at the interface of the ceramic and backing plate, opposite to the impact location. The deceleration and erosion of the impacting projectile is caused at a rate determined by the yield strength of the projectile and hardness of the ceramic. Ceramics which are hard, abrasive and tough (at high strain rates) than the projectile will cause it to break up and flow. The pulverizing of projectile continues even after the cracking of ceramic. Hence, some authors estimated the friction resistance of this powder in arresting the momentum (Cortez et al 1992). Delaying the initiation of tensile failure in ceramic allows for more projectile erosion. A higher compressive strength of ceramic increases the ballistic response, especially in thick targets (Anderson and Morris 1992). Transfer of momentum from projectile to a larger volume of ceramic, which is ejected at a high velocity is the major arresting interaction. The backing should sustain the deformation due to the remnant force and improves the ballistic performance of ceramic. A glassceramic has much in common with a ceramic and the fracture behaviour is quite similar.

\section{Ballistic resistance}

Ballistic resistance tests are methods for building a database for comparison of armour materials. These tests are often of destructive nature involving many variables such as the velocity of threat, nature of target and support materials, impact point on the target etc.

Ballistic velocity limit is a measure of the maximum velocity that a given amount of material will defeat. This is design-specific and applies only for that projectile and target. V50 is defined as the velocity with $50 \%$ probability.for perforating a target at normal incidence. V50 tests are for smaller arms. But the procedure is expensive, as it is destructive and has too much scatter. Depth of penetration (DOP) is another test proposed wherein the penetration depth of the backing plate, which supports the target 
is evaluated (Cortez et al 1992). We have compared 5 tiles with DOP method. The five tiles, A, B, C, D, E were subjected to firing tests. The tiles were supported on thick $(50 \mathrm{~mm})$ FRP boards. They were impacted with $7.62 \mathrm{~mm}$ round balls at a distance of $10 \mathrm{~m}$ with velocities $\sim 830 \mathrm{~m} / \mathrm{s}$. Table 1 lists the velocities and DOP for the tiles. The back panels (after the impact) are shown in figure 3. The DOP was very low and there was some scatter owing to the fibre pull-outs. The maximum depth measured is shown in the table. It was almost alike for B, D and E i.e. a thick glassceramic, its coating on
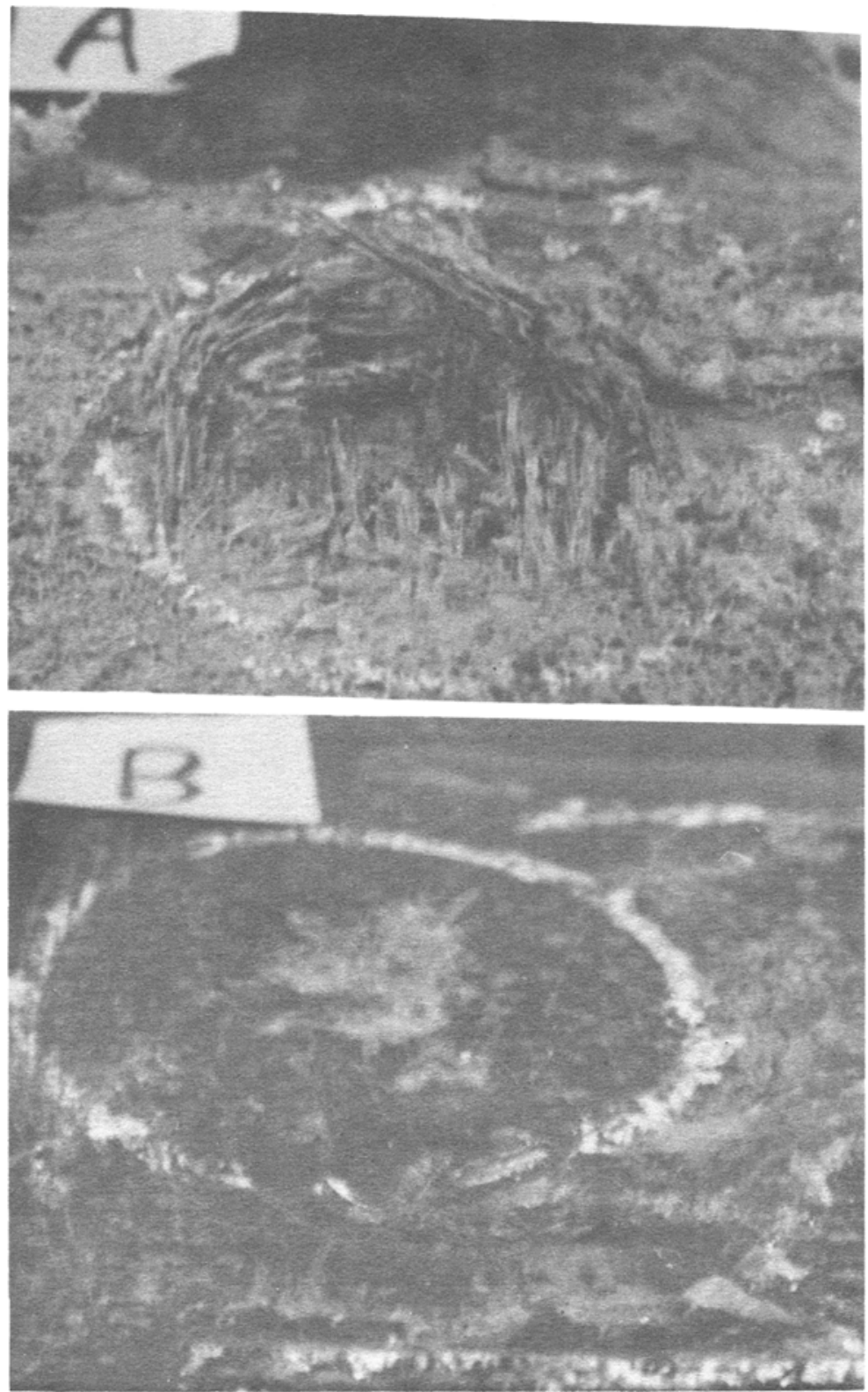

Figure 3. A-B. 

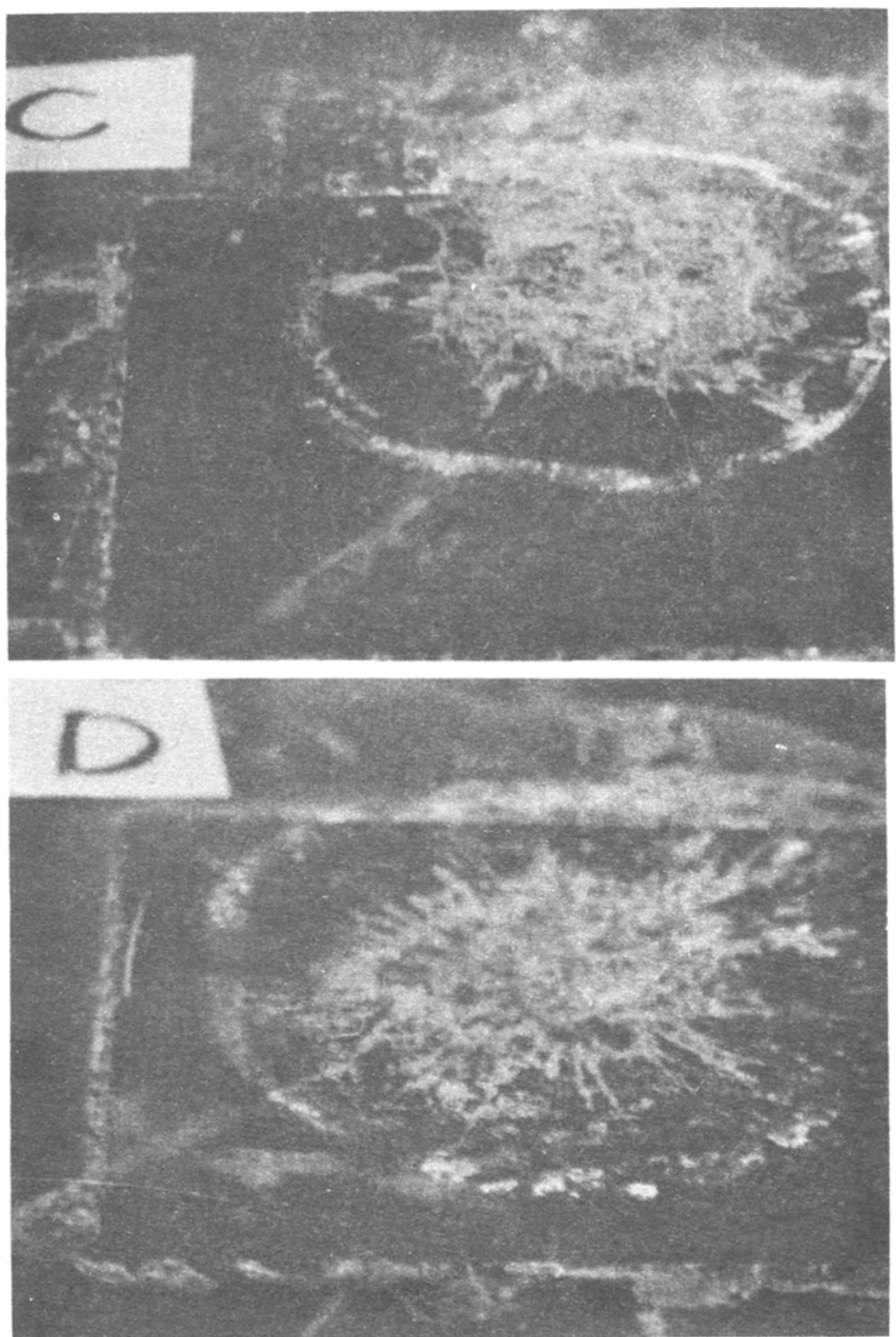

Figure 3. C-D. 


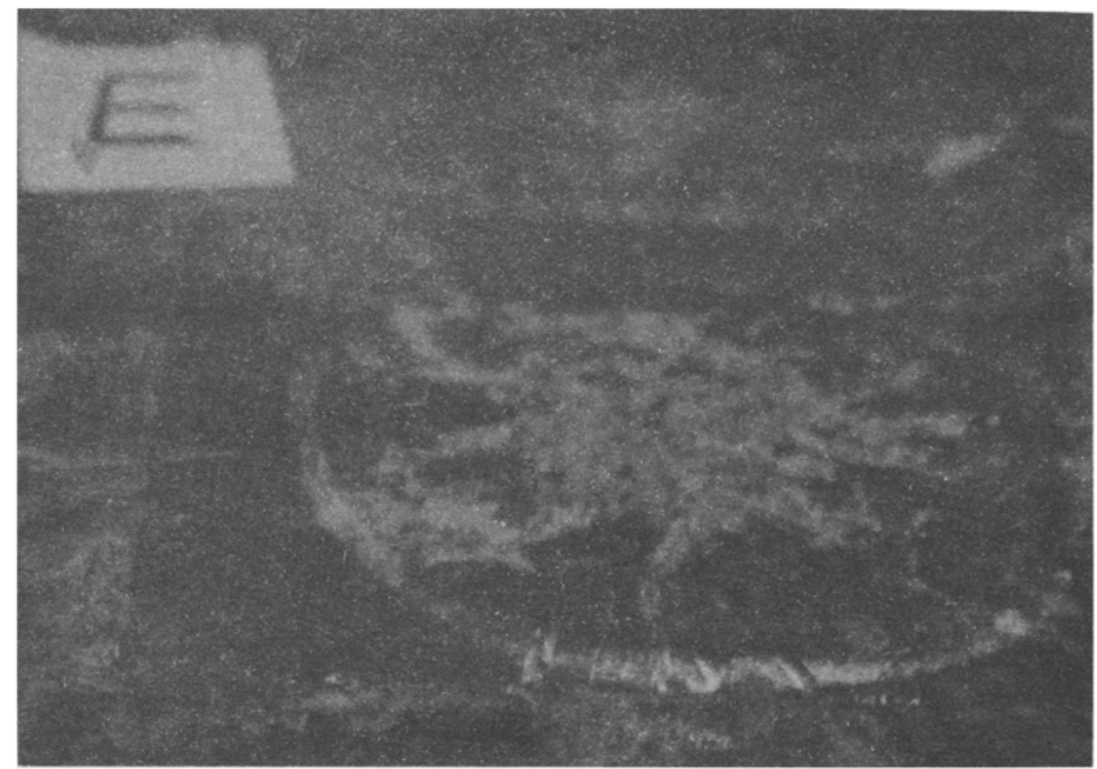

Figure 3. FRP panels after the firing of tiles A, B, C. D. and E.

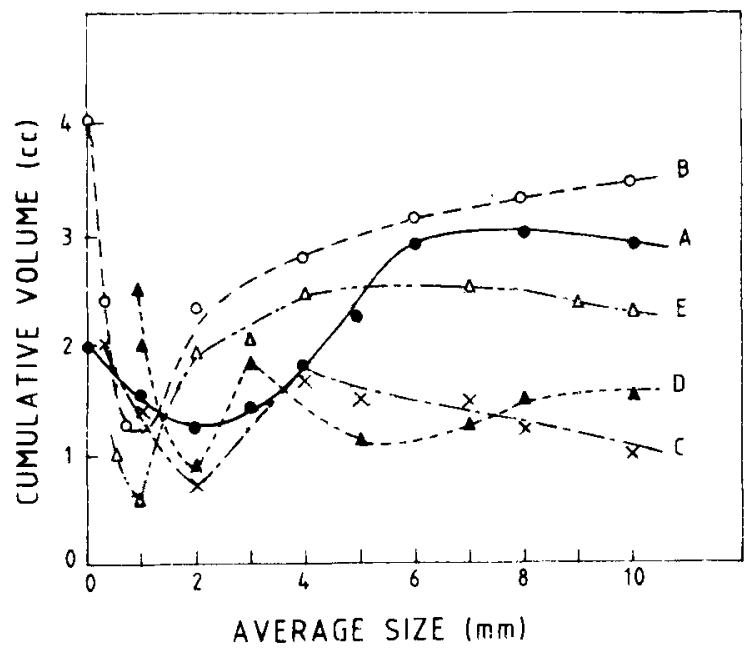

Figure 4. Cumulative volume of fragments against average size.

alumina and alumina. On comparing their areal densities, the ballistic resistance seem to be almost similar.

\section{Fragmentation behaviour}

The shattered pieces of tiles were collected after the firing. The visible metal pieces of the eroded projectile were removed from the debris. Fragmented pieces were separated 

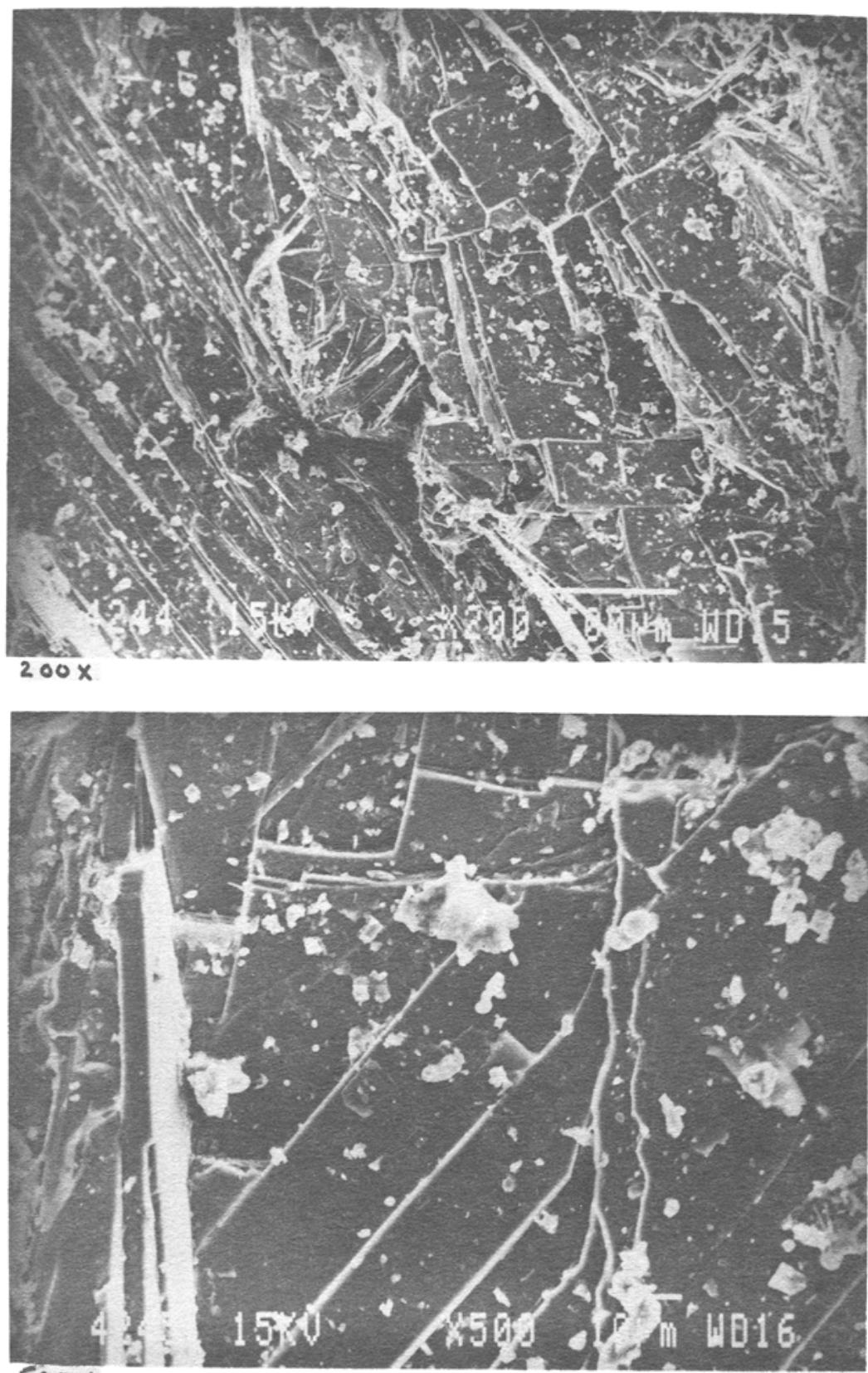

$500 x$

Figure 5. Microstructure of the fragmented piece showing the crystallites and the fine lead powder (identified from EDX).

according to size. Fine powders were sieved through known mesh sizes. Bigger pieces were removed manually. Cumulative mass for a particular size can be obtained from the weight. Cumulative volume can be directly evaluated from displacement techniques conventionally used for density measurements. Figure 4 shows the plot of cumulative 
volume against average fragment size. A linear relation is expected (Woodward et al 1989), but there are deviations for small and large sizes. The large sizes are away from impact spot. For small sizes, less than 1 or $2 \mathrm{~mm}$ the mass and volume are high because the debris contained eroded projectile which had a lead core. This is reflected in the measured density of the powder. The EDX analysis of the micrographs of fragments (figure 5) showed submicron sizes of lead. This demonstrates that the projectile had been well-pulverized. As the hardness of glassceramics and alumina are higher than lead an effective pulverization has taken place.

The surface area created (the energy of fragmentation) pertains to the energy dissipated, and, hence, relates to the ballistic performance. The total surface area created on impact $S$, is related to the toughness $T$ and the work done $W$ as, $W=T S / 2$ (Woodward et al 1989). It shows an inverse relation between surface area created and toughness. For a tougher ceramic like alumina the surface area created would be less. This can be seen in figure 4 . The glassceramics show larger cumulative volume of fragments. B shows the largest cumulative volume and the lowest DOP.

On impact, which is an inelastic collision process, the projectile energy is dissipated in the fracture of target, the erosion of projectile, the deformation of backing plate and remaining as the kinetic energy of fragments. Woodward et al (1989) analysed the distribution in energy dissipations as, for the plastic deformation of backing plate $20-40 \%$, deformation of the projectile $10-15 \%$ and the kinetic energy of debris $45-70 \%$. For small calibre projectiles only $0.2 \%$ of kinetic energy was spent in the fracture of ceramic. For glasses and glassceramics even less, about $0.02 \%$. The insignificance of some properties of target materials at high velocities of projectile is thus understandable. O'Donnell (1992) tests on several ceramics brought out no clear correlation between the ceramic fragments, toughness and ballistic resistance. Impact at high velocities is a complex collision process. More statistics is needed before unambiguous conclusions are made.

Reinforcements and chemical processes can strengthen and improve the toughness of glassceramics further, while keeping the densities low. Combining glassceramics with alumina can be advantageous as the flaws on its surface are smoothened. By increasing the volume of coating the effective density of tile is reduced causing some weight saving as well.

\section{Conclusions}

The depth of penetration tests show that glassceramics compare with alumina in ballistic resistance for impacts at velocities about $830 \mathrm{~m} / \mathrm{s}$ and have some advantage on weight saving and formability. Pulverizing of the projectile was complete. Fragmentation size distributions show large cumulative volume for glassceramics. With reinforcements to improve the toughness values the glassceramics could become competitive to alumina as an armour material.

\section{Acknowledgements}

The author thanks Shri R Nagabushana Rao for arranging the target tests and Shri N V Viswararao for the patient sizing of fragments. Thanks are due to the Director, DMRL for his support. 


\section{References}

Anderson C E and Morris B L 1992 Int. J. Impact Eng. 12167

Cortez R, Navarro C, Martinez M A, Rodriguez J and Sanchez-Galvez V 1992 Int. J. Impact. Eng. 12639 Jones R W and Todhunter R 1988 Indian Ceram. 8201

Laible R C (ed.) 1980 in Ballistic materials and penetration mechanics (Amsterdam, Netherlands: Elsevier) Macmillan P W 1979 in Glassceramics (London: Academic Press)

O'Donnell R G 1992 J. Mater. Sci. Letts. 111227

Saraswati V 1992 Technical report, DMRL TR92160

Saraswati V and Sriram S 1989 Met. Mater. Proc. 121

Wilkins M L 1980 in Ballistic materials and penetration mechanics (ed.) R C Laible (Amsterdam, Netherlands: Elsevier)

Woodward R L, O’Donnell R G, Baxter B J, Nicol B and Pattie S D 1989 Mater. Forum 13174 